\title{
Affective archives as political impasse
}

\author{
Margarita Palacios ${ }^{1,2} \cdot$ Derek Hook $^{3,4}$
}

Accepted: 16 November 2020 / Published online: 3 December 2020

(c) The Author(s), under exclusive licence to Springer Nature Limited part of Springer Nature 2020

This special issue presents work of the multidisciplinary and international Affective Archives Research Group that was established in 2016. The aim of the group was to reflect upon the multiple intersections between the affective and aesthetico-political as they occur at various global sites and impact upon various instantiations of subjectivity. We put forward in this issue a number of novel analytical approaches to political and epistemological formations of archives of affect while approaching domains of aesthetics and memorialization as repositories of emotionality and subjectivity. The Affective Archives Group provides an exemplification of the research agenda described in the first issue of Subjectivity, namely, the aim to

bring together scholars from across the social sciences and the humanities in a collaborative project to identify the processes by which subjectivities are produced, to explore subjectivity as a locus of social change, and examine how emerging subjectivities remake our social worlds (Blackman et al. 2008, p. 1).

Extending this research program, the Affective Archives Group conceptualized a series of contemporary transactions and channelings of affect as means of social (dis)ordering and political intervention. As became evident in the deliberations of the research group, such approaches needed to remain open and undecided in their theoretical scope, varied in the 'methodologies' developed. The group aimed, furthermore, to remain receptive to questions of knowledge production, and fundamentally exploratory in how to understand the engendering of political affects at various global locations.

Following two international research meetings (June 2017 in London, and September 2018, Pittsburgh), we decided to go forward with a special issue to foreground the work of its members. The special issue shows the diversity of the conceptual frameworks and geographical sites that the group has explored in tracking

Margarita Palacios

mpalaciosb@yahoo.com

1 Department of Psychosocial Studies, Birkbeck College, University of London, London, UK

2 Institute of Philosophy, Universidad Diego Portales, Santiago, Chile

3 Duquesne University, Pittsburgh, PA, USA

4 University of Pretoria, Pretoria, South Africa 
various political modalities of affect. More than this, the special issue foregrounds a recurring and persistent theme that emerged in the context of our collaborative discussions: forms of political impasse. This theme undoubtedly characterizes the dire state of our current global political situation, in which a conservative agenda routinely pre-empts, outflanks or bypasses the ideals of a progressive politics. The notion of political impasse proves a fruitful and generative motif, a means of approaching the inertia of affective change in a cross-section of different sites, from the fraught terrain of "white innocence", to an investigation of (in)animate bodies in extractive capitalism, from a consideration of mapping practices to an engagement with the concept of death-bound subjectivity in contexts of white supremacy, from discussions of Frantz Fanon's idea of the zone of nonbeing to the 'enlarged thought' of post-colonial critique that can be traced via an analysis of a nightmare of Nelson Mandela's. But political impasse also refers to the very opening, as well as opaqueness, of archives of affects, and their capacity to destabilize gendered and racialized narratives and exclusionary practices and cartographies. In our Special Issue, Affective Archives as Political Impasse we weave together epistemological questions and their genealogies, with relevant aesthetico-political interventions in a variety of contemporary settings.

The first paper in the special issue, Helene Strauss's Energy Archives: Of Rocks, Rubbish, and Feminist feeling in Aliki Saraga's 'Strike a Rock', provides an innovative cross-disciplinary feminist critique not only of violent extractivism but of its echoing effects across generations. More specifically, Strauss attends to the affective charge of rocks and rubbish as they exist in multiple and overlapping (material, symbolic, aesthetic and archival) forms. In a thoughtful discussion, Strauss highlights how Saraga's 'Strike a Rock' highlights the means by which local women have negotiated enduring types of political and economic impasse in their communities. Drawing on key facets of the anthrodecentric or 'new materialist' turn in recent social and cultural theorizing, Strauss provides an instructive-and historically-grounded-analysis of extractive capitalism's historical exploitation of mineral, mechanical, muscular and psychic energies. Strauss's concluding hope is that creative and activist energies might be put in the service of regenerative rather than extractive projects, indeed, that such projects might, as she puts is, "make geontopower's destructive governing of difference and markets visible beyond the purview of communities most explicitly and violently subjected to it".

Margarita Palacios and Stephen Sheehi's Vaporizing White Innocence, puts forward a radical critique to the aesthetic and affect that informs 'white innocence' and its attempts at witnessing the pain of the Other. Engaging with the work of critical race theorists they put Dana Shutz's Open Casket in conversation with Teresa Margolles' Vaporization. The paper explores the epistemological, affective and aesthetic dimensions involved in the desire of whiteness to transcend its own matrix of race-power and aestheticization of black suffering. The argument put forward is that instead of anti-racist and transformative, Schutz's piece remains caught within a Manichean subject/object relationship constituted by a curative relation of mastery and servitude that is inextricably contained with and by the ontology of whiteness. They argue that this dynamic of 'pornotroping' mobilizes an aesthetics of hailing and identification that reaffirms white innocence. Margolles' Vaporization, on the 
other hand, is seen as compelling to engage the space, corporality, and epistemology of flesh outside of the subject/object divide, while confronting us with multiplicities of embodiment as experienced through art and social productions.

Simonetta Moro's Mapping Practices and The Cartographic Imagination aims to highlight the mutual intersections of space and intersubjectivity, while investigating the affective relationship between territory, place, map/mapping, borders, and subjectivity. As she claims, "subjectivity not only cannot lie beyond historical specificity, but similarly, it cannot lie beyond geographical specificity". In order to pursue this, Moro engages in an intertextual reading of Heidegger's late essay "Building Dwelling Thinking" with some key themes in Deleuze and Guattari's work, as well as the deployment of examples of artistic cartography where the appearance of the map exposes current political impasse in a globalized world. The argument put forward is that maps and the "act of mapping" have the capacity to disrupt symbolic horizons concerning representations of space constructing aesthetic, political and subjective worldviews while offering a redefinition of mapping as "assemblage or gathering point of the fourfold". This redefinition indicates, according to her, the becoming-space of a narration that constitutes particular kinds of world views and subjectivities.

How might Nelson Mandela's dream-life inform our understanding of the affective archives of post-apartheid subjectivity and culture? In Dreaming of Freedom from the Perspective of Everyone, Ross Truscott develops an incisive

reading of Sharon Sliwinski's Mandela's Dark Years: A Political Theory of Dreaming. Sliwinski's text explores how Mandela's dreams from the period of his incarceration on Robben Island not only stages scenes of racial oppression but also, crucially, influenced his judgment of apartheid and his concept of freedom. While noting the value of such an analytical exercise, Truscott advances two associated lines of critique pertaining to Sliwinski's project. In the first of these, Truscott picks up two Kantian notions - the sublime and the idea of enlarged thought - that Sliwinski uses to qualify Mandela's political thought. Significantly, both of these Kantian notions stem from Kant's discourse on disinterested reflection and aesthetic judgment. The second line of critique develops a psychoanalytic reading of Mandela's dreams which is notably distinct from Sliwinski's. In this respect, Truscott foregrounds the themes of childhood wishes, the death drive, and-perhaps surprisingly-the postal system. In the final sections of the paper, Truscott combines his two lines of critique to the ends of scrutinizing facets of Kantianism as they appear within psychoanalysis. He also asks: what within Mandela's thought troubles disinterested reflection, what, moreover, might implicate it - and accordingly, any psychoanalytic approach to dreams of freedom-in the very violence against which Mandela fought?

In 'Aberrations of affect', The Critique of Ontology and the Specificity of the Colonial Relation Efthimios Karayiannides turn his attentions to the work of the revolutionary figure who seems more than any other to personify the urgency of the agendas of decolonization and the Black Lives Matter Movement: Frantz Fanon. As they note, with the increasing spread and influence of Fanon's work there has been a temptation to ontologize aspects of his analysis of colonialism. This impetus takes a variety of forms, and serves varying agendas. It can be seen in attempts to highlight 
the overarching ambivalence of all social identities just as it can in assertions of the absolute specificity of Blackness. Despite the prospective critical insights and/or conceptualizations engendered by such initiatives, a central problem remains. Ontologizations of Fanon's ideas obscure the ways in which he, Fanon, claimed that his own examination of the colonial situation necessarily broke with traditional ontology. Through an examination of Fanon's deployment of the Sartrean concept of 'the situation' and the comparisons he draws in his psychiatric writings between workplace management techniques and racist societies Karayiannides shows how Fanon sought to think simultaneously the specificity of anti-Black racism and the resolutely modern ways in which it is constantly reproduced.

Is there a particular form of political agency that emerges from the conditions of death-bound subjectivity? This is Derek Hook's question in his contribution to this special issue: Death-bound subjectivity: Fanon's Zone of Nonbeing and the Lacanian death drive. Hook's paper begins by citing the prescient comments of Steve Biko, the martyred South African Black Consciousness revolutionary, on death and political hope, before moving to consider an adjoined site of resistance-an adjoined affective archive - namely, that outlined by Frantz Fanon's concept of the zone of nonbeing. This zone, oft revisited in the secondary literature on Fanon, is conceptualized by Fanon himself as enabling radical forms of resistance. What though effectively underlies and drives the passionate modes of resistance and agency that can be engendered in this zone of nonbeing? What psychical factors make the agency of death-bound agency viable? One prospective answer to this question lies in Lacan's reconceptualization of the death as ethical cause. The Lacanian death drive-a dramatic departure from the original Freudian conceptualization of a 'death instinct' - is explored by Hook as a mode of surplus life which underlies an unceasing fidelity to a cause. More than just this, the death drive can, following Lacan's account in The Ethics of Psychoanalysis, be said to deliver the subject to a zone between life and death. Presenting the Lacanian death drive as a prospective auxiliary concept to Fanon's zone of nonbeing, Hook offers a novel conceptualization of the agency of radical negativity-indeed, of death-bound subjectivity - that the abyssal zone of nonbeing makes possible.

Acknowledgements We would like to thank all of the colleagues and friends who collaborated within us at the two Affective Archives events in London and Pittsburgh. We are likewise thankful for the researching funding and support provided by our respective institutions (Birkbeck College and Duquesne University), and for the tireless editorial assistance of Isabel Waidner. We owe also a debt of gratitude to the editors of Subjectivity, Lisa Blackman and Valerie Walkerdine, for being so supportive in respect of this special issue.

\section{References}

Blackman, L., J. Cromby, D. Hook, D. Papadopoulas, and V. Walkerdine. 2008. Creating subjectivities. Subjectivity 22: 1-27.

Publisher's Note Springer Nature remains neutral with regard to jurisdictional claims in published maps and institutional affiliations. 
Margarita Palacios is Senior Lecturer of Social Theory at the Department of Psychosocial Studies, Birkbeck College University of London and Associate Researcher at the Institute of Philosophy, Universidad Diego Portales, Santiago, Chile. She is the author of Violence and Political Fantasy (Wiesbaden, 2009), and Radical Sociality: Studies on Disobedience, Violence and Belonging (2013). Her last articles include "The Aesthetics of Memory: Ruins, Visibility and Witnessing" (The Sociological Review, 2019) and "A Critique of Populist Aesthetics of Homogeneity" (Theory and Event, 2020).

Derek Hook is an Associate Professor of Psychology at Duquesne University and an Extraordinary Professor of Psychology at the University of Pretoria. He is the author of A Critical Psychology of the Colonial (2011), (Post)apartheid Conditions (2013) and Six Moments in Lacan (2017). In addition to acting as a co-editor with Calum Neill on the Palgrave Lacan Series, he is also the editor of Lie on Your Wounds: The Collected Prison Correspondence of Robert Mangaliso Sobukwe. He has a YouTube channel with 50+ mini lectures on Lacanian Psychoanalysis which can be accessed at: https://www.youtube.com/chann el/UCzdZyq2SC9BtMn3fLTknIMQ. 